\title{
Impaired Microvascular Dilatation and Capillary Rarefaction in Young Adults with a Predisposition to High Blood Pressure
}

\author{
Joseph P. Noon, ${ }^{\star}$ Brian R. Walker, ${ }^{\star}$ David J. Webb, ${ }^{\star}$ Angela C. Shore, ${ }^{\ddagger}$ David W. Holton, ${ }^{\S}$ Hugh V. Edwards, ${ }^{\S}$ \\ and Graham C.M. Watt \\ *Department of Medicine, University of Edinburgh, Western General Hospital, Edinburgh EH4 2XU, United Kingdom; ${ }^{\ddagger}$ Department of \\ Vascular Medicine, University of Exeter, Postgraduate Medical School, Exeter EX2 5AX, United Kingdom; ${ }^{\circledR}$ Ladywell Medical Centre,

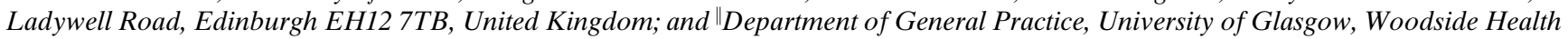 \\ Centre, Barr Street, Glasgow G20 7LR, United Kingdom
}

\begin{abstract}
Increased vascular resistance in essential hypertension occurs mainly in microvessels with luminal diameters $<100$ $\mu \mathrm{m}$. It is not known whether abnormalities in these vessels are a cause or consequence of high blood pressure (BP). We studied 105 men (aged 23-33 yr) in whom predisposition to high blood pressure has been characterized by both their own BP and those of their parents. Factors that are secondary to high BP correlate with offspring BP irrespective of parental BP, but factors that are components of the familial predisposition to high $\mathrm{BP}$ are more closely associated with higher BP in offspring whose parents also have high BP.

Offspring with high BP whose parents also have high BP had impaired dermal vasodilatation in the forearm following ischemia and heating $(289 \pm 27[n=25]$ versus $529 \pm 40$ $[n=26], 476 \pm 38[n=30]$, and $539 \pm 41$ flux units [ $n=24]$ in other groups; $P<0.0001)$ and fewer capillaries on the dorsum of the finger $\left(23 \pm 0.8\right.$ capillaries $/ 0.25 \mathrm{~mm}^{2}$ versus $26 \pm 0.8$ in all other groups; $P<0.003)$. Except for BP, other hemodynamic indices (including cardiac output and forearm vascular resistance) were not different.

The dermal vessels of men who express a familial predisposition to high BP exhibit increased minimum resistance and capillary rarefaction. Defective angiogenesis may be an etiological component in the inheritance of high BP. $(J$. Clin. Invest. 1997. 99:1873-1879.) Key words: blood vessels • blood pressure $\bullet$ hypertension $\cdot$ genetics $\bullet$ hemodynamics
\end{abstract}

\section{Introduction}

Peripheral vascular resistance is dictated primarily by resistance across vessels $<100 \mu \mathrm{m}$ in luminal diameter (1). Micropuncture studies show that capillary pressures are elevated in essential hypertension (2) while venous pressure is normal (3),

Address correspondence to Professor David J. Webb, Clinical Pharmacology Unit, University of Edinburgh, Department of Medicine, Western General Hospital, Edinburgh EH4 2XU, Scotland, UK. Phone: +44 131332 1205; FAX: +44 131343 6017; E-mail: d.j.webb@ed.ac.uk

Received for publication 18 September 1996 and accepted in revised form 30 January 1997.

J. Clin. Invest.

(C) The American Society for Clinical Investigation, Inc.

0021-9738/97/04/1873/07 \$2.00

Volume 99, Number 8, April 1997, 1873-1879 suggesting that capillary or postcapillary vascular resistance is increased. The characteristic increase in peripheral vascular resistance in essential hypertension is, therefore, likely to reflect structural or functional changes in these microvessels (4). Structural abnormalities in vessels of hypertensive patients include decreased luminal diameter, predominantly in larger arterioles $(5,6)$, but also in capillaries $(7,8)$, and a reduction in the density of vessels per volume of tissue (known as rarefaction), which occurs predominantly in the smallest vessels (2, 7-13). Functional abnormalities of microvessels in established essential hypertension include reduced capillary blood flow in the basal state (14) and reduced vasodilatation induced by heating (15). The latter may be a functional consequence of abnormal structure since increased resistance in vessels which are maximally dilated is the hallmark of structural change $(5,16)$.

From studies in established hypertension, it is not possible to ascertain whether microvascular abnormalities are a cause or consequence of the rise in blood pressure. Circumstantial evidence suggests that they are causal, because they occur early in the development of hypertension (9) and are not closely correlated with other consequences of hypertension such as increased left ventricular mass (17). In an attempt to distinguish microvascular abnormalities which could cause high blood pressure from those which are a consequence of high blood pressure, we have studied subjects from a novel four corners epidemiological model (18-22) in which subjects are identified as having either high or low blood pressure in early adulthood, and are further classified on the basis of their parents' blood pressures. Factors which are associated with higher blood pressure in offspring irrespective of parental blood pressure are more likely to be secondary to high blood pressure, or to be influenced by environmental determinants of blood pressure which occur in all offspring. By contrast, factors which are associated with higher blood pressure only in offspring whose parents' blood pressures are high may be contributing to the expression of the familial predisposition to high blood pressure.

\section{Methods}

Subjects and study design. In 1977 during the screening phase of the Medical Research Council Mild Hypertension Trial (23), blood pressure was measured in 1,809 married couples at the Ladywell Medical Centre, Edinburgh, Scotland. In 1985, blood pressure was measured in 864 offspring (aged 16-24 yr) from 603 of these families. Offspring blood pressure was plotted against mean parental blood pressure using age-adjusted $\mathrm{Z}$ scores (see Fig. 1). The population was then divided in tertiles for both offspring and parental blood pressure to identify individuals who were members of one of the four corners of the 
plot (OH/PL: offspring blood pressure high, parental blood pressure low; OH/PH: offspring blood pressure high, parental blood pressure high; OL/PL: offspring blood pressure low, parental blood pressure low; OL/PH: offspring blood pressure low, parental blood pressure high). ${ }^{1}$ Subgroups of offspring randomly selected from each corner have participated in previous investigations (19-22).

In 1993-95, we studied male offspring drawn at random from each of the four corners (see Table I). The clinical investigator performing the studies (Joseph P. Noon) did not know from which corner subjects were drawn until data collection and analysis were complete. No subjects were taking relevant medication. Local ethical committee approval and informed consent were obtained.

After an overnight fast from 2200 hours, and abstention from proprietary drugs including aspirin for $10 \mathrm{~d}$, subjects attended the clinical research center at 0900 hours. Height and weight were recorded before subjects lay supine and acclimatized to a controlled environmental temperature of $23-24^{\circ} \mathrm{C}$. After $20 \mathrm{~min}$, recordings of blood pressure and cardiac function were made. After $40 \mathrm{~min}$, the following observations were made in sequence: $(a)$ in the right arm, maximum vasodilatation of skin microvessels was measured by laser Doppler fluximetry (MBF3D; Moor Instruments Ltd., Axminster, UK) in response to two stimuli: local heating to $42^{\circ} \mathrm{C}$, followed by the addition of a period of ischemia; $(b)$ in the left arm, nailfold capillary blood velocity and red cell column width, and capillary numbers on the dorsum of the ring finger, were measured by intravital videomicroscopy; and $(c)$ in the right arm, forearm blood flow was measured before and after ischemia, using strain gauge plethysmography (PMS Instruments, Maidenhead, UK). The protocol was completed by 1130 hours.

Blood pressure and cardiac function. Blood pressure was recorded four times at 5-min intervals using a random-zero sphygmomanometer (Hawksley \& Sons Ltd., West Sussex, UK) (24) as in previous phases of the study. Because of the recent controversy over the accuracy of this device (25), for calculations of vascular resistance we repeated each measurement using a semiautomated machine (UA 751 sphygmomanometer; Takeda Medical Inc., Tokyo, Japan) which has been independently validated (26). The means of the last three recordings were used in subsequent analyses. Mean arterial pressure was calculated as diastolic blood pressure + (pulse pressure $\div 3$ )

Measurements of cardiac output and stroke volume were made using a noninvasive bioimpedance method (NCCOM3; BoMed Medical Manufacturing Ltd., Irvine, CA) (27). Results were divided by body surface area to give cardiac index and stroke index, respectively. Peripheral vascular resistance was calculated as mean arterial pressure with Takeda instrument $\div$ cardiac index.

Forearm blood flow. Forearm blood flow was measured using venous occlusion plethysmography (28) with temperature-compensated indium/gallium in silastic strain gauges calibrated on the limb, as previously described (29). In brief, during 3-min recording periods, a wrist cuff was inflated to $220 \mathrm{mmHg}$ to exclude the hand circulation, and flows were measured for $10 \mathrm{~s}$ in every $15-\mathrm{s}$ interval by repeated inflation of an upper arm congesting cuff to $40 \mathrm{mmHg}$. After basal recordings, the upper arm cuff was inflated to $220 \mathrm{mmHg}$ for $12 \mathrm{~min}$, and recordings were made for the first $60 \mathrm{~s}$ after release of the cuff (i.e., during the maximum reactive hyperemic period) $(30,31)$. The slopes of the final five recordings from each period were averaged to determine flow, and forearm vascular resistance was calculated as mean arterial pressure with Takeda instrument $\div$ forearm blood flow.

1. Abbreviations used in this paper: $\mathrm{OH}$, offspring with blood pressure in the upper third of the population; OL, offspring with blood pressure in the lower third of the population; $\mathrm{PH}$, offspring of parents with mean blood pressure in the upper third of the population; PL, offspring of parents with mean blood pressure in the lower third of the population.

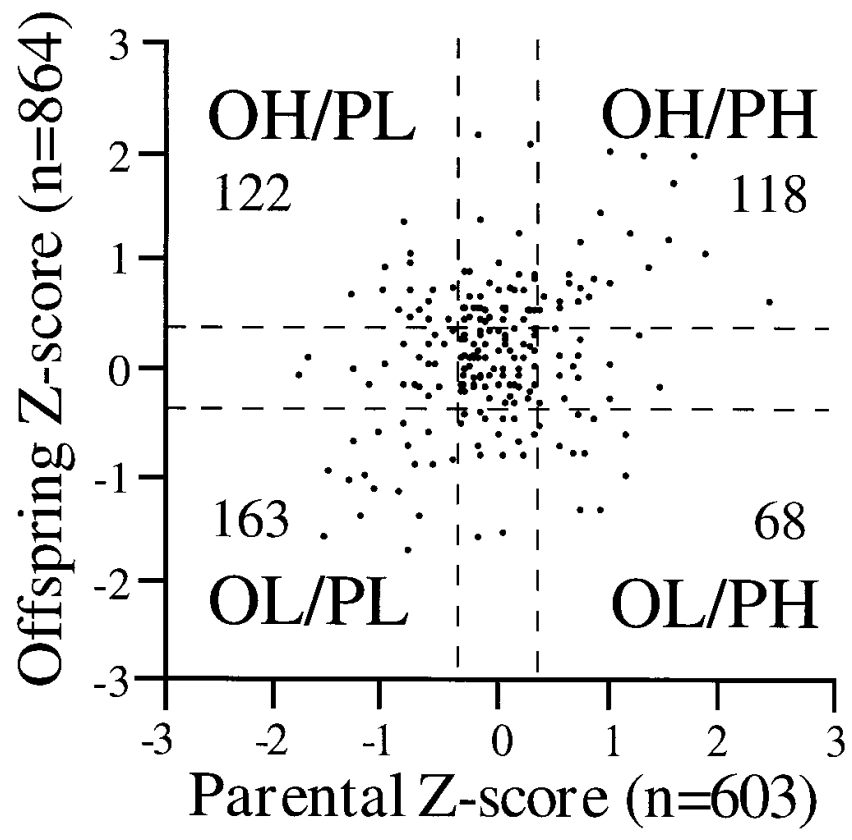

Figure 1. The four corners model of contrasting predisposition to high blood pressure. Blood pressures are plotted as Z-scores (i.e., SDs from the age-adjusted mean) for offspring and as Z-scores of the arithmetic mean for parents. The dashed lines show the cutoffs ( $\pm 0.35 \mathrm{SD})$ used to define corners containing at least 50 offspring. The number of offspring in each corner are shown. These figures include both males and females, but only males were used in the current study. Only a representative sample of the data points are shown for clarity.

\section{Dermal vasodilatation}

Dermal blood flow was estimated by laser Doppler fluximetry (Moor Instruments Ltd.). Probes were calibrated with flux standard each day. Linearization circuitry was included, but, at the bandwidth of $14.9 \mathrm{kHz}$, there was loss of linearity in vitro with flux $>300 \mathrm{U}$. For this reason, differences between groups may be underestimated rather than overestimated at hyperemic flow rates between 300 and $1,000 \mathrm{U}$. Also for this reason, calculation of dermal vascular resistance was inappropriate, and statistical analyses were performed on flux measurements.

Responses to two stimuli (heat alone and heat following ischemia) were examined. During ischemia, nonflow-related flux (biological zero) was measured and subtracted from all other recordings.

Local heating. The skin of the right forearm was preheated to $36^{\circ} \mathrm{C}$ using warm air, and a $1-\mathrm{cm}$ diameter brass skin warmer (Skin Temperature Controller; Moor Instruments Ltd.) was applied to the volar surface (32). Skin temperature was recorded under the warmer using a Fluke $52 \mathrm{~K} / \mathrm{J}$ digital thermometer (RS components, Corby, UK) and maintained at $42^{\circ} \mathrm{C}$ for $30 \mathrm{~min}$. A laser Doppler probe was inserted into a channel in the warmer that could be rotated to allow flux to be recorded for $30 \mathrm{~s}$ at each of eight different sites. The mean of these recordings was used in further analysis. The intrasubject coefficient of variation for this measurement was $8.5 \pm 0.3 \%$.

Post-ischemic hyperemia. While heating continued, an upper arm cuff was inflated to $220 \mathrm{mmHg}$ for $5 \mathrm{~min}$, and flux was measured at a single site for $30 \mathrm{~s}$ after releasing the cuff. The mean flux during these $30 \mathrm{~s}$ was used for further analysis.

Capillaroscopy. Capillaries were visualized using a microscope (Leitz; Leica UK, Milton Keynes, UK) and recorded on videocassette with a television camera (Phillips LDH0703; KRP Power Source, Newbury, UK) (33). 
Finger nailfold capillary loops lie parallel to the skin surface where movement of blood cells within the capillaries can be visualized. To minimize variations in blood flow attributable to rhythmical variation in individual capillaries (34) and to differences between capillaries (35), subjects were studied at the same time of day, and at the same environmental temperature, by a single investigator (J.P. Noon). Six different microscopy fields randomly selected from across the nailfold were each recorded for $2.5 \mathrm{~min}$. Capillary blood velocity was measured in the arterial limbs of six randomly selected capillaries using computerized photometric temporal correlation. Red cell column width was measured at 3 sites on the arteriolar limb of each of the six capillaries using computerized window splitting (Kista S-16440; CapiFlow, Stockholm, Sweden) (36). Red cell column width is a surrogate measure of luminal diameter assuming that the width of the plasma layer at the margins of the red cell column remains constant between corners. Intrasubject coefficients of variation were $31 \pm 2 \%$ for capillary blood velocity, and $14 \pm 1 \%$ for red cell column width.

In some subjects it was impossible to visualize as many as six capillary loops due to damage or injury to the cuticle of the nail (e.g., in manual workers or nail-biters). These subjects were excluded from further analysis, so that studies were completed for 20 subjects from corner $\mathrm{OH} / \mathrm{PL}, 22$ from corner $\mathrm{OH} / \mathrm{PH}, 21$ from corner OL/PL, and 20 from corner $\mathrm{OL} / \mathrm{PH}$. There were no significant differences between participating and excluded subjects from any corner for any of the other variables recorded (data not shown).

To measure capillary numbers, the summits of capillary loops were visualized end-on in the dermis of the dorsum of the second phalanx of the left ring finger. Perfused capillaries (i.e., those contain-

Table I. Demographic, Hemodynamic, and Capillaroscopy Data for Subjects from the Four Corners of the Study

\begin{tabular}{|c|c|c|c|c|c|c|}
\hline $\begin{array}{l}\text { Offspring blood pressure } \\
\text { Parental blood pressure }\end{array}$ & $\begin{array}{l}\text { Low } \\
\text { Low }\end{array}$ & $\begin{array}{l}\text { High } \\
\text { Low }\end{array}$ & $\begin{array}{l}\text { Low } \\
\text { High }\end{array}$ & $\begin{array}{l}\text { High } \\
\text { High }\end{array}$ & Analysis of variance* & $\begin{array}{c}95 \% \mathrm{CI} \text { for } \mathrm{OH} / \mathrm{PH} \\
\text { vs. } \mathrm{OL} / \mathrm{PL}^{\ddagger}\end{array}$ \\
\hline$n$ & 30 & 26 & 24 & 25 & & \\
\hline Age range (mean in yr) & $23-32(29)$ & $23-32(28)$ & $25-32(28)$ & $23-33(29)$ & $P=0.47$ & \\
\hline No. of smokers & 7 & 6 & 7 & 6 & $\left(\chi^{2} \mathrm{NS}\right)$ & \\
\hline Height (m) & $1.81 \pm 0.01$ & $1.80 \pm 0.01$ & $1.77 \pm 0.01$ & $1.78 \pm 0.01$ & $P=0.09$ & +0.001 to +0.059 \\
\hline Weight $(\mathrm{kg})$ & $78.9 \pm 2.3$ & $79.1 \pm 2.1$ & $73.0 \pm 2.0$ & $80.4 \pm 2.5$ & $P=0.12$ & -8.3 to +5.3 \\
\hline Body mass index & $24.1 \pm 0.6$ & $24.4 \pm 0.5$ & $23.4 \pm 0.6$ & $25.4 \pm 0.7$ & $P=0.11$ & -3.1 to +0.5 \\
\hline $\begin{array}{l}\text { Systolic blood pressure } \\
\text { (mmHg by Hawksley) }\end{array}$ & $111 \pm 1$ & $118 \pm 1$ & $111 \pm 2$ & $123 \pm 2$ & $\begin{array}{c}P<0.0001 \\
\text { OH/PL vs. OH/PH, } \\
\text { OL/PL,PL/PH. } \\
\text { OH/PH vs. OL/PL,OL/PH. }\end{array}$ & -16 to -8 \\
\hline $\begin{array}{r}\text { Diastolic blood pressure } \\
(\mathrm{mmHg} \text { by Hawksley) }\end{array}$ & $72 \pm 1$ & $78 \pm 1$ & $73 \pm 1$ & $82 \pm 2$ & $\begin{array}{c}P<0.0001 \\
\text { OH/PL vs. OH/PH, } \\
\text { OL/PL,OL/PH. }\end{array}$ & \\
\hline Mean arterial pressure $(\mathrm{mmHg})$ & $85 \pm 1$ & $91 \pm 1$ & $86 \pm 1$ & $96 \pm 2$ & $\begin{array}{c}\mathrm{OH} / \mathrm{PH} \text { vs. OL/PL, OL/PH. } \\
P<0.0001 \\
\mathrm{OH} / \mathrm{PL} \text { vs. OH/PH. } \\
\text { OL/PL,OL/PH. }\end{array}$ & -14 to -6 \\
\hline Pulse rate (beats per min) & $58 \pm 2$ & $65 \pm 2$ & $58 \pm 1$ & $65 \pm 2$ & $\begin{array}{l}\mathrm{OH} / \mathrm{PH} \text { vs. OL/PL,OL/PH. } \\
\qquad P<0.004 \\
\text { OH/PL vs. OL/PL,OL/PH. }\end{array}$ & -15 to -7 \\
\hline Cardiac index (dyn.min. $m^{-5}$ ) & $4.0 \pm 0.1$ & $4.3 \pm 0.2$ & $3.9 \pm 0.2$ & $4.5 \pm 0.2$ & $\begin{array}{c}\mathrm{OH} / \mathrm{PH} \text { vs. OL/PL, OL/PH. } \\
\qquad P=0.10\end{array}$ & $\begin{array}{l}-13 \text { to }-1 \\
-0.95 \text { to }-0.05\end{array}$ \\
\hline Stroke index $\left(1 \cdot \mathrm{min}^{-1} \cdot \mathrm{m}^{-2}\right)$ & $67 \pm 2$ & $65 \pm 3$ & $64 \pm 3$ & $65 \pm 3$ & $P=0.87$ & -5 to +9 \\
\hline $\begin{array}{l}\text { Peripheral vascular resistance } \\
\text { index }\left(\text { dyn. min. } \mathrm{cm}^{-5} \cdot \mathrm{m}^{-2}\right)\end{array}$ & $20.8 \pm 0.6$ & $21.5 \pm 1.1$ & $22.2 \pm 1.0$ & $21.8 \pm 1.2$ & $P=0.77$ & -3.6 to +1.6 \\
\hline $\begin{array}{l}\text { Basal forearm vascular resistance } \\
\quad\left(\mathrm{mmHg} \cdot \mathrm{m}^{-1} \cdot \min .100 \mathrm{ml}\right)\end{array}$ & $38.8 \pm 2.6$ & $43.6 \pm 3.5$ & $44.2 \pm 3.2$ & $39.8 \pm 2.3$ & $P=0.40$ & -8.1 to +6.1 \\
\hline $\begin{array}{l}\text { Minimal forearm vascular resistance } \\
\quad \text { (nonsmokers only) } \\
\quad\left(\mathrm{mmHg} \cdot \mathrm{ml}^{-1} \cdot \min .100 \mathrm{ml}\right)\end{array}$ & $\begin{array}{c}2.4 \pm 0.2 \\
(2.1 \pm 0.2)\end{array}$ & $\begin{array}{c}2.5 \pm 0.2 \\
(2.5 \pm 0.2)\end{array}$ & $\begin{array}{c}2.8 \pm 0.3 \\
(2.2 \pm 0.1)\end{array}$ & $\begin{array}{c}2.8 \pm 0.1 \\
(3.0 \pm 0.4)\end{array}$ & $\begin{array}{l}P=0.30 \\
P=0.07\end{array}$ & -0.88 to +0.08 \\
\hline $\begin{array}{l}\text { Dermal flux Biological Zero } \\
\text { (arbitrary units) }\end{array}$ & $7.4 \pm 0.7$ & $7.5 \pm 0.6$ & $7.8 \pm 0.5$ & $7.3 \pm 0.8$ & $P=0.96$ & -2.07 to +2.28 \\
\hline Capillary blood velocity $\left(\mathrm{mm} \cdot \mathrm{sec}^{-1}\right)$ & $\begin{array}{l}1.2 \pm 0.1 \\
(n=21)\end{array}$ & $\begin{array}{l}1.4 \pm 0.2 \\
(n=20)\end{array}$ & $\begin{array}{l}1.3 \pm 0.2 \\
(n=20)\end{array}$ & $\begin{array}{l}1.0 \pm 0.1 \\
(n=22)\end{array}$ & $P=0.50$ & -0.08 to +0.49 \\
\hline Red cell column width $(\mu \mathrm{m})$ & $\begin{array}{l}8.9 \pm 0.3 \\
(n=21)\end{array}$ & $\begin{array}{l}9.2 \pm 0.3 \\
(n=20)\end{array}$ & $\begin{array}{l}9.1 \pm 0.2 \\
(n=20)\end{array}$ & $\begin{array}{l}9.0 \pm 0.3 \\
(n=22)\end{array}$ & $P=0.80$ & -0.96 to +0.76 \\
\hline
\end{tabular}

* When $P<0.004$ for analysis of variance, subsequent comparisons between corners refer to $P<0.05$ for Fisher's two-group probability of least squares difference test. ${ }^{\ddagger} 95 \%$ confidence intervals (CI) are given for unpaired two-tail Student's $t$ test of values for corner OH/PH versus corner OL/ PL. These corners have the greatest contrast in predisposition to high blood pressure. 
ing erythrocytes) were counted in 60-s recordings from each of six fields of $0.5 \times 0.5 \mathrm{~mm}$, calibrated with a graticule micrometer (Graticules Ltd., Tonbridge, UK), both before and during venous occlusion with a digital cuff (Peni-Cuff; Hokanson, Bellevue, WA) inflated to $40 \mathrm{mmHg}$ for $10 \mathrm{~min}$ to expose nonperfused capillaries. This technique was successful in all study participants. Intrasubject coefficients of variation were $8 \pm 1$ for basal capillary number, and $7 \pm 1 \%$ for capillary number during venous occlusion.

Statistical analyses. The primary hypothesis was that microvascular structure and function are different between corners, and this impacts on hemodynamic variables. Statistical comparisons were limited to the 11 variables which test this hypothesis (i.e., BP, pulse rate, cardiac index, stroke index, peripheral vascular resistance, basal and minimum forearm vascular resistance, maximal dermal blood flow, capillary blood velocity, red cell column width, and capillary number) and to possible confounding factors. Comparisons of each variable across the four corners was by factorial analysis of variance. A Bonferroni correction was applied for the 11 principal variables, whereby differences between the four corners were considered significant when $P<0.004$ (i.e., $0.05 \div 11$ ). Where appropriate, analysis of variance was followed by comparison of pairs of corners by Fisher's probability of least squares difference test. The effects of smoking were examined by two-factor analysis of variance, with corner allocation and smoking status as controlling variables. Results are mean \pm SEM.

The statistical power to detect differences between groups varied considerably between different measurements. For example, $90 \%$ confidence of detecting differences at the $5 \%$ level could be achieved with only 13 subjects in each group for a $40 \%$ difference in maximal dermal blood flow, and 10 subjects in each group for a $15 \%$ difference in capillary numbers, but 27 in each group for a $40 \%$ difference in minimal forearm vascular resistance. These variations in power need to be considered in the interpretation of data in Table I. To this end, confidence intervals $(95 \%)$ are shown in the table for the observed differences between corners $\mathrm{OH} / \mathrm{PH}$ and OL/PL because these corners contain subjects with the greatest contrast in their predisposition to high blood pressure.

\section{Results}

Blood pressure and cardiac function. Blood pressures were higher in corners $\mathrm{OH} / \mathrm{PL}$ than in OL/PL, and higher in $\mathrm{OH} / \mathrm{PH}$ than in OL/PH (Table I). In addition, blood pressures were significantly higher in corner $\mathrm{OH} / \mathrm{PH}$ than in corner $\mathrm{OH} / \mathrm{PL}$. Heart rate was higher in corners $\mathrm{OH} / \mathrm{PL}$ than in OL/PL, and higher in $\mathrm{OH} / \mathrm{PH}$ than in $\mathrm{OL} / \mathrm{PH}$. Cardiac index, stroke index, and total peripheral vascular resistance were not significantly different among corners. The $95 \%$ confidence intervals of the differences, however, were wide for cardiac index, there being a trend towards higher values in corners $\mathrm{OH} / \mathrm{PL}$ than in OL/ $\mathrm{PL}$ and higher values in $\mathrm{OH} / \mathrm{PH}$ than in $\mathrm{OL} / \mathrm{PH}$. Smoking did not influence any of these variables (Table I).

Forearm vascular resistance. There were no differences among corners in forearm vascular resistance either in the basal state or after ischemia (Table I). Smoking, however, had an influence (2-factor ANOVA $P=0.06$ ) such that if smokers were excluded from the analysis, forearm vascular resistance was marginally higher in corner $\mathrm{OH} / \mathrm{PH}$ (Table I).

Dermal vasodilatation. Biological zero flux was not different among groups (Table I). Flux after both local heating and ischemia were reduced in offspring with high BP only if parental $\mathrm{BP}$ was high (i.e., lower in corner $\mathrm{OH} / \mathrm{PH}$ than in $\mathrm{OL} / \mathrm{PH}$, but not different between corners OH/PL and OL/PL) (Fig. 2). Smoking did not influence these variables (data not shown).

Capillaroscopy. There were no differences among corners for capillary blood velocity or luminal diameter, as judged by (a)
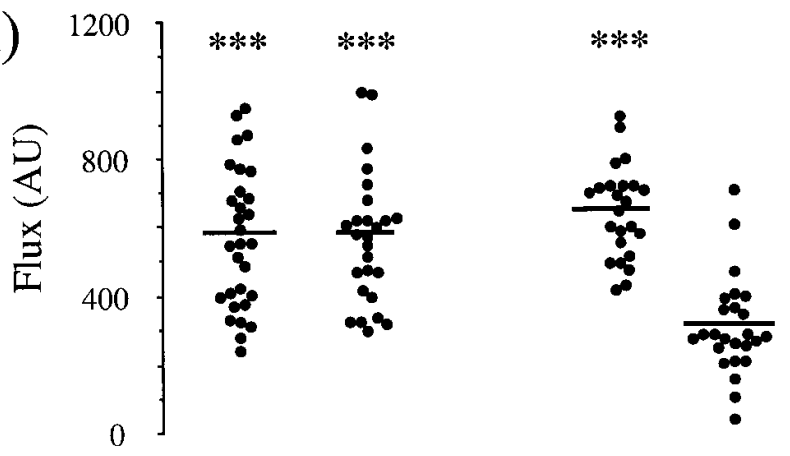

(b)

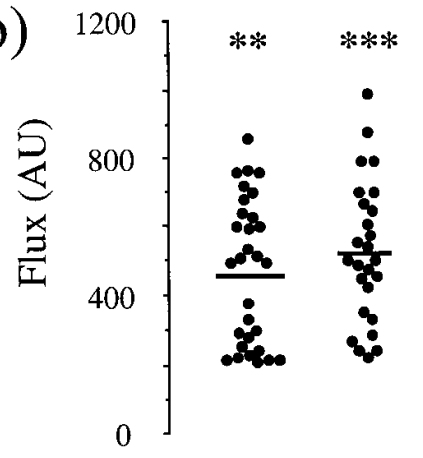

$\begin{aligned} \text { Offspring BP: } & \text { Low High } \\ \text { Parental BP: } & \text { Low Low }\end{aligned}$

Low High

High High

Figure 2. Dermal vasodilatation in response to heat and ischemia in subjects from the four corners. Increasing flux was measured after heating to $42^{\circ} \mathrm{C}(a)$ and, in addition, after $5 \mathrm{~min}$ ischemia $(b)$. Bars are means. Analysis of variance for the four corners was significant to $P<0.0001$ for both variables, and $P$ values shown refer to subsequent comparison of corners with corner OH/PH by Fisher's probability of least squares difference test. ${ }^{* *} P<0.001$; $* * * P<0.0001$.

red cell column width (Table I). 95\% confidence intervals of the differences, however, were wide for capillary blood velocity, there being a trend towards lower values in corner $\mathrm{OH} / \mathrm{PH}$.

Capillary numbers were not different among corners in the basal state, although they tended to be lower in smokers (data not shown; ANOVA $P=0.07)$. During venous occlusion they were markedly lower in corner $\mathrm{OH} / \mathrm{PH}(P<0.003)$, not different among any other corners (Fig. 3), and not influenced by smoking.

\section{Discussion}

The four corners epidemiological design is a novel attempt to distinguish familial and nonfamilial correlates of high blood pressure, which may provide a means of differentiating factors which are nonspecific consequences of high blood pressure from factors that are associated with the expression of a familial predisposition to high blood pressure. The model has been discussed in greater detail elsewhere $(19,37)$. The definition of the predisposition to high blood pressure using the four corners approach is more precise than that which can be achieved using conventional epidemiological methods based on offspring or parental blood pressure alone because conventional methods select heterogenous groups of subjects who could be- 


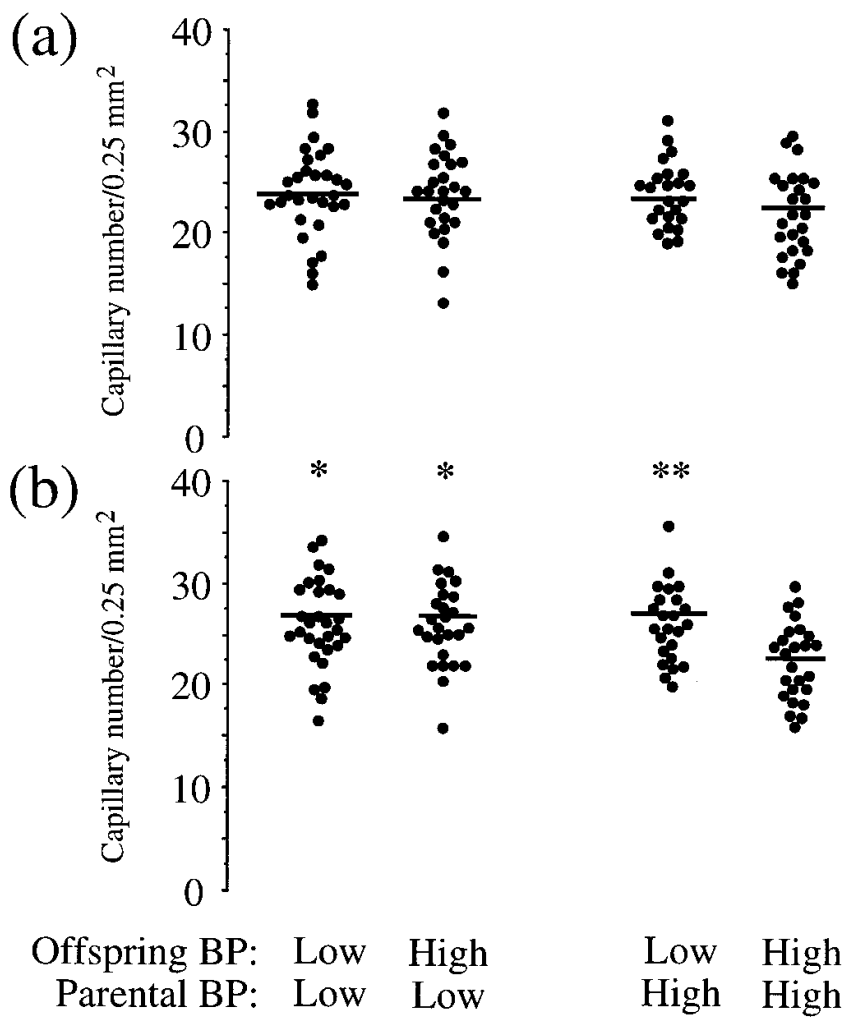

Figure 3. Capillary numbers in subjects from the four corners. Capillary numbers were measured in the basal state $(a)$ and during venous occlusion $(b)$. Bars are means. Analysis of variance for the four corners was significant to $P<0.003$ for capillary numbers during venous occlusion, and $P$ values shown refer to subsequent comparison of corners with corner $\mathrm{OH} / \mathrm{PH}$ by Fisher's probability of least squares difference test. $* P<0.01 ; * * P<0.001$.

long to either of two corners, or to areas in upper and lower tertiles which lie between the corners (Fig. 1). Therefore, it is possible that biological differences will be detected among the four corners which would not be detected by much larger conventional studies. It is important to recognize that $55 \%$ of the study population are included in the definition of the four corners so that we are studying factors which might influence the distribution of blood pressure in a population rather than factors which are associated with the clinical definition of essential hypertension. Also, while the familial predisposition may be genetic, it may also be environmental.

The characteristics of offspring originally allocated to different corners in 1985 are proving to be remarkably consistent. In 1985, mean arterial pressure in the 240 males from the four corners was $95 \mathrm{mmHg}$ in corner $\mathrm{OH} / \mathrm{PL}, 98 \mathrm{mmHg}$ in $\mathrm{OH} / \mathrm{PH}$, $75 \mathrm{mmHg}$ in $\mathrm{OL} / \mathrm{PL}$, and $77 \mathrm{mmHg}$ in OL/PH (19). Measurements taken 8-9 yr later (Table I) show that the differences in blood pressure between the corners are increasing. Blood pressure has changed most in corner $\mathrm{OH} / \mathrm{PH}$, the group for whom both offspring and parental blood pressures were high. These observations confirm that blood pressure tracks with age (38), and suggest that the combination of parental and offspring blood pressures provides a more accurate prediction of the subsequent development of high blood pressure than either parental or offspring blood pressure alone. The fact that blood pressure is now higher in corner $\mathrm{OH} / \mathrm{PH}$ than in corner $\mathrm{OH} / \mathrm{PL}$ means that the use of corner $\mathrm{OH} / \mathrm{PL}$ as a control group with a nonfamilial elevation in blood pressure is no longer straightforward. Nevertheless, there remain larger differences in blood pressure between corners OH/PL and OL/PL and between corners $\mathrm{OH} / \mathrm{PH}$ and $\mathrm{OL} / \mathrm{PH}$ than between corners $\mathrm{OH} /$ $\mathrm{PH}$ and $\mathrm{OH} / \mathrm{PL}$. The absence of any difference in the variables measured in our study between corners OH/PL and OL/PL remains the strongest evidence that observed differences between corners $\mathrm{OH} / \mathrm{PH}$ and $\mathrm{OL} / \mathrm{PH}$ are not secondary to higher blood pressure alone.

We used this unique population to help to distinguish primary and secondary abnormalities of microvascular structure and function which are associated with high blood pressure. The hallmarks of structural change in vessels are an increase in minimum vascular resistance and decrease in maximal blood flow (5). We observed a remarkably large (more than 50\%) reduction in maximal dermal blood flow in subjects with high blood pressure only if their parents had high blood pressure. This pattern provides strong evidence against enhanced dermal vascular resistance being a secondary consequence of higher blood pressure, and is consistent with the biologically plausible hypothesis that it is a primary abnormality that contributes to the familial predisposition to high blood pressure. It remains possible, however, that enhanced dermal vascular resistance is not a primary abnormality, because no observational study can distinguish factors that cause high BP from factors which cosegregate with high $\mathrm{BP}$ but are not involved in its etiology.

The observation of a twofold difference in dermal blood flow is unlikely to be accounted for by functional abnormalities such as increased sympathetic tone, since we have shown that maximal dermal dilatation induced under these conditions cannot be reversed by sympathetic stimuli such as gasp-induced vasoconstriction (Shore et al., unpublished observation). Nor was the difference in maximal blood flow attributable to smoking, or to a difference in capillary luminal diameter. Associated with this evidence of structural change in dermal vessels in subjects from corner $\mathrm{OH} / \mathrm{PH}$, however, we observed a trend towards lower capillary blood velocity and a reduced capillary number consistent with capillary rarefaction.

Arterioles with luminal diameters of $20-400 \mu \mathrm{m}$ have previously been demonstrated to have an increased wall/lumen ratio in established hypertension as a consequence of vascular hyperplasia and/or remodeling (4-6). Our data suggest that the luminal narrowing which occurs in capillaries in essential hypertension $(7,8)$ is not present in subjects predisposed to high blood pressure, and is therefore possibly not of pathogenetic importance. In the present study, however, we have not examined the structure of larger arterioles directly. There is a contribution to minimum dermal vascular resistance from larger arterioles (4), and we cannot exclude the possibility that luminal narrowing in these vessels contributes to the marked differences in dermal blood flow which we observed.

By contrast, the difference we observed in capillary numbers was striking, and only present in offspring with high blood pressure whose parents also have high blood pressure (Fig. 3). The hemodynamic impact of microvascular rarefaction is controversial, and differs greatly among vascular beds according to the extent of interarteriolar and arteriolar-venular anastomoses. Calculations by computer modeling of in vivo beds predict an exponential relationship between vessel number and 
vascular resistance (39). For example, loss of $42 \%$ of third order arterioles in the hamster cheek pouch would increase vascular resistance by $21 \%$ (40). We observed a $14 \%$ difference in capillary number during venous occlusion in subjects who express a familial predisposition to high blood pressure (Fig. 3), a difference which is similar in magnitude to the $17 \%$ rarefaction observed in established hypertension (2), and which could explain the decrease in maximal dermal blood flow. Total peripheral vascular resistance and minimum forearm vascular resistance (principally determined by resistance in skeletal muscle), however, are increased in patients with essential hypertension $(16,31)$ and in their normotensive relatives (41). We found no difference among corners for these variables, albeit that there was a trend towards elevated minimal forearm vascular resistance in nonsmokers in corner $\mathrm{OH} / \mathrm{PH}$. This raises the possibility that microvascular abnormalities associated with the expression of familial predisposition to high blood pressure are limited to specific vascular beds, for example, affecting dermal vessels, but not forearm skeletal muscle vessels. On the other hand, the variance of measurements of forearm and systemic vascular resistance is greater than measurements in the skin, and the absolute difference in blood pressure is relatively small between corners, so we may not have detected a difference in forearm or systemic vascular structure where one exists. The contribution of dermal vascular resistance to total peripheral vascular resistance is relatively small depending on the environmental temperature, and it will be important to establish whether other vascular beds, such as the mesenteric and renal vessels, also exhibit rarefaction and increased resistance. It may be that other vascular beds develop these abnormalities at a later stage, perhaps as a consequence of elevated blood pressure.

The mechanism of capillary rarefaction may be either structural, associated with capillary attrition or impaired angiogenesis, or functional, associated with impaired recruitment of nonperfused capillaries during stimulation (42). It appears that both mechanisms operate in subjects who express a familial predisposition to high blood pressure since basal capillary numbers were not significantly different, but recruitment of capillaries during venous occlusion was markedly impaired in corner $\mathrm{OH} / \mathrm{PH}$. Thus, structural capillary rarefaction is associated with almost maximal recruitment of capillaries in the basal state so that the incremental functional change with venous occlusion is smaller. The observation that a smaller proportion of capillaries are nonperfused in the basal state in subjects from corner $\mathrm{OH} / \mathrm{PH}$ raises the possibility that their microvessels are exposed to higher systemic perfusion pressures for longer periods than normal. In due course this may promote the microvascular pathology which develops with essential hypertension.

If the capillary rarefaction that we have observed is structural, it may be explained by impaired angiogenesis. This hypothesis could explain the relationships between adult hypertension and growth in intrauterine life, childhood, and puberty (38). Barker and colleagues have demonstrated that adults with higher blood pressure are born with lower birth weight (43). Hypertensive adults, however, are more obese than normotensive controls. In our subjects, the expression of the familial predisposition to high blood pressure occurs in subjects of higher body weight when it is associated with shorter height (Table I) (19). It may be that, because of faster rates of catchup growth in later life, hypertensive subjects outgrow their vascular tree, thereby having to recruit more capillaries to continuous perfusion, resulting in accelerated structural microvascular changes and hypertension.

In summary, we have shown that impaired microvascular vasodilatation and capillary rarefaction are associated with the expression of familial predisposition to essential hypertension in young adult males. By contrast, capillary luminal diameter and blood flow are not reduced at this stage in the development of high blood pressure, and these are more likely to be consequences rather than causes of elevated blood pressure. We conclude that the factors which influence microvascular growth and anatomy deserve more detailed attention as potential candidate mechanisms in the pathogenesis of hypertension.

\section{Acknowledgments}

Our thanks to Professors S.B. Harrap and A.F. Lever, and Mr. C.J.W. Foy, who were influential in developing the Ladywell study; Dr. R. Elton for statistical advice; Dr. R. Gush of Moor Instruments and the staff of the Medical Physics Department, Western General Hospitals NHS Trust for their technical support; Moor Instruments Ltd., Millwey, Axminster, Devon, UK, for providing the laser Doppler equipment; and the volunteers associated with the Ladywell Medical Centre in Edinburgh for their continuing support.

Grant support was from the Scottish Home and Health Department, the High Blood Pressure Foundation, and the Wellcome Trust.

\section{References}

1. Struijker-Boudier, H.A.J., J.L.M.L le Noble, M.W.J. Messing, M.S.P Huijberts, F.A.C. le Noble, and H. van Essen. 1992. The microcirculation and hypertension. J. Hypertens. 10 (Suppl. 7):147-156.

2. Williams, S.A., M. Boolell, G.A. MacGregor, L.H. Smaje, S.M Wasserman, and J.E. Tooke. 1990. Capillary hypertension and abnormal pressure dynamics in patients with essential hypertension. Clin. Sci. (Lond.). 79:5-8.

3. Widgren, B.R., G. Berglund, J. Wiskrand, and O.K. Andersson. 1992. Reduced venous compliance in normotensive men with positive family histories of hypertension. J. Hypertens. 10:459-465.

4. Shore, A.C., and J.E. Tooke. 1994. Microvascular function in human essential hypertension. J. Hypertens. 12:717-728.

5. Folkow, B. 1990. "Structural Factor" in primary and secondary hypertension. Hypertension (Dallas). 16:89-101.

6. Heagerty, A.M., C. Aalkjær, S.J. Bund, N. Korsgaard, and M.J. Mulvany. 1993. Small artery structure in hypertension: dual processes of remodelling and growth. Hypertension (Dallas). 21:391-397.

7. Landau, J., and E. Davis. 1957. Capillary thinning and high capillary blood pressure in hypertension. Lancet. i:1327-1330.

8. Harper, R.N., M.A. Moore, M.C. Marr, L.E. Watts, and P.M. Hutchins 1978. Arteriolar rarefaction in the conjunctiva of human essential hypertensives. Microvasc. Res. 16:369-372.

9. Sullivan, J.M., R.L. Prewitt, and J.A. Josephs. 1983. Attenuation of the microcirculation in young patients with high-output borderline hypertension. Hypertension (Dallas). 5:844-851.

10. Henrich, H.A., W. Romen, E. Heimgartner Hartung, and F. Baumer 1988. Capillary rarefaction characteristic of the skeletal muscle of hypertensive patients. Klin. Wochenschr. 66:54-60.

11. Williams, S.A., J.E. Tooke, and G. MacGregor. 1986. Rarefaction of skin capillaries in hypertension. Clin. Sci. (Lond.). 70 (Suppl. 13):14P.

12. Gasser, P., and F.R. Bühler. 1992. Nailfold microcirculation in normotensive and essential hypertensive subjects, as assessed by video-microscopy. $J$. Hypertens. 10:83-86.

13. Prasad, A., G.S. Dunhill, P.S. Mortimer, and G.A. MacGregor. 1995. Capillary rarefaction in the forearm skin in essential hypertension. J. Hypertens. 13:265-268.

14. Duprez, D., M. de Buyzere, T. de Backer, J. Vercammen, F. Brusselmans, and D.L. Clement. 1992. Impaired microcirculation in mild-to-moderate essential arterial hypertension. J. Hypertens. 10:251-254.

15. Williams, S.A., and J.E. Tooke. 1992. Noninvasive estimation of increased structurally-based resistance to blood flow in skin of subjects with essential hypertension. Int. J. Microcirc. Clin. Exp. 11:109-116.

16. Folkow, B., G. Grimby, and O. Thulesius. 1958. Adaptive structural changes of the vascular walls in hypertension and their relation to the control of peripheral resistance. Acta Physiol. Scand. 44:255-272.

17. Lucarini, A.R., M. Spessot, E. Picano, C. Marini, F. Lattanzi, R. 
Pedrinelli, and A. Salvetti. 1991. Lack of correlation between cardiac mass and arteriolar structural changes in mild-to-moderate hypertension. J. Hypertens. 9: 1187-1191.

18. Watt, G.C.M., C.J.W. Foy, D.W. Holton, and H.V. Edwards. 1991. Prediction of high blood pressure in young people: the limited usefulness of parental blood pressure data. J. Hypertens. 9:55-58.

19. Watt, G.C.M., S.B. Harrap, C.J.W. Foy, D.W. Holton, H.V. Edwards, H.R. Davidson, J.M. Connor, A.F. Lever, and R. Fraser. 1992. Abnormalities of glucocorticoid metabolism and the renin-angiotensin system: a four corners approach to the identification of genetic determinants of blood pressure. J. Hypertens. 10:473-482.

20. Harrap, S.B., H.R. Davidson, J.M. Connor, F. Soubrier, P. Corvol, R. Fraser, C.J.W. Foy, and G.C.M. Watt. 1993. The angiotensin I converting enzyme gene and predisposition to high blood pressure. Hypertension (Dallas). 21:455-460.

21. Harrap, S.B., N.J. Samani, D. Lodwick, J.M. Connor, R. Fraser, D.L. Davies, A.F. Lever, C.J.W. Foy, and G.C.M. Watt. 1995. The $\mathrm{S}_{\mathrm{A}}$ gene: predisposition to hypertension and renal function in man. Clin. Sci. (Lond.). 88:665-670.

22. Harrap, S.B., A.F. Dominiczak, R. Fraser, A.F. Lever, J.J. Morton, C.J. Foy, and G.C.M. Watt. 1996. Plasma angiotensin II, predisposition to hypertension and left ventricular size in healthy young adults. Circulation. 93:1148-1154.

23. Greenburg, G. 1985. MRC trial of treatment of mild hypertension: principal results. Br. Med. J. 291:97-104.

24. Wright, B.M., and C.F. Dore. 1970. A random-zero sphygmomanometer. Lancet. i:337-338.

25. Conroy, R.M., E. O'Brien, K. O’Malley, and N. Atkins. 1993. Measurement error in the Hawksley random zero sphygmomanometer: what damage has been done and what can we learn? Br. Med. J. 306:1319-1322.

26. Wiinberg, N., S. Walter-Larson, C. Eriksen, and P.E. Nielsen. 1988. An evaluation of semi-automatic blood pressure manometers against intra-arterial blood pressure. J. Amb. Monitor. 1: 303-309.

27. Northridge, D.B., I.N. Findlay, J. Wilson, E. Henderson, and H.J. Dargie. 1990. Non-invasive determination of cardiac output by Doppler echocardiography and electrical bioimpedance. Br. Heart. J. 63:93-97.

28. Whitney, R.J. 1953. The measurement of volume changes in human limbs. J. Physiol. (Lond.). 121:1-27.

29. Webb, D.J. 1995. Pharmacology of human blood vessels in vivo. J. Vasc. Res. 32:2-15.

30. Patterson, G.C., and R.F. Whelan. 1955. Reactive hyperaemia in the hu- man forearm. Clin. Sci. (Lond.). 14:197-209.

31. Pedrinelli, R., M. Spessot, and A. Salvetti. 1990. Reactive hyperaemia during short-term blood flow and pressure changes in the hypertensive forearm. J. Hypertens. 8:467-471.

32. Rayman, G., S.A. Williams, P.D. Spencer, L.H. Smaje, P.H. Wise, and J.E. Tooke. 1986. Impaired microvascular hyperaemic response to minor skin trauma in type 1 diabetes. Br. Med. J. 292:1295-1298.

33. Flynn, M.D., S.A. Williams, and J.E. Tooke. 1989. Clinical television microscopy. J. Med. Eng. Technol. 13:278-284.

34. Fagrell, B., A. Fronek, and M. Intaglietta. 1977. A microscope-television system for studying flow velocity in human skin capillaries. Am. J. Physiol 233:318-321.

35. Östergren, J. 1984. Skin capillary circulation in man studied by videophotometric capillaroscopy. Ph.D. thesis. Karolinska Institute, Repro Print AB, Stockholm.

36. Fagrell, B., L. Rosen, and S.E. Eriksson. 1994. Comparison between a new computerized and an analogue videophotometric, cross correlation technique for measuring skin capillary blood velocity in humans. Int. J. Microcirc. Clin. Exp. 14:133-138.

37. Anon. 1992. Genetics of hypertension. Lancet. 339:1142-1143.

38. Lever, A.F., and S.B. Harrap. 1992. Essential hypertension: a disorder of growth with origins in childhood? J. Hypertens. 10:101-120.

39. Hudetz, A.G. 1993. Percolation phenomenon: the effect of capillary network rarefaction. Microvasc. Res. 45:1-10.

40. Greene, A.S., P.J. Tonellato, J. Lui, J.H. Lombard, and A.W. Cowley. 1989. Microvascular rarefaction and tissue vascular resistance in hypertension. Am. J. Physiol. 256:126-131.

41. Takeshita, A., T. Imaizumi, T. Ashihari, K. Yamamoto, S. Hoka, and M. Nakamura. 1982. Limited maximal vasodilator capacity of forearm resistance vessels in normotensive young men with a familial predisposition of hypertension. Circ. Res. 50:671-677.

42. Prewitt, R.L., and D.H. Wang. 1991. The importance of differences in the pressure profile of the arterial bed. In Resistance Arteries: Structure and Function. M.J. Mulvany, C. Aalkjær, A.M. Heagerty, N.C.B. Nyborg, and S. Strandgaard, editors. Excerpta Medica International Congress Series, Amsterdam. 61-65.

43. Barker, D.J.P., A.R. Bull, C. Osmond, and S.J. Simmonds. 1990. Fetal and placental size and risk of hypertension in adult life. Br. Med. J. 301:259-262. 